\title{
Circulating adrenaline and noradrenaline concentrations during exercise in patients with exercise induced asthma and normal subjects
}

\author{
K E BERKIN, G WALKER, G C INGLIS, S G BALL, N C THOMSON
}

From the Department of Respiratory Medicine and the Medical Research Council Blood Pressure Unit, Western Infirmary, Glasgow, and the Department of Physiology, University of Glasgow

ABSTRACT A failure of the usual increase in plasma adrenaline and noradrenaline concentrations during submaximal exercise has been suggested as a contributory cause of exercise induced asthma. Six normal subjects and six asthmatic patients underwent a standard graded maximal exercise test. Measurements of oxygen consumption, minute ventilation, exercise time, blood lactate concentration, and heart rate indicated that the two groups achieved similarly high work loads during exercise. Mean FEV, fell by $20 \%$ in asthmatic patients after exercise. Basal plasma adrenaline concentrations $(\mathrm{nmol} / \mathrm{l})$ increased in normal subjects from 0.05 to 2.7 and in asthmatic patients from 0.12 to 1.6 at peak exercise. Noradrenaline concentrations (nmol/l) increased in normal subjects from $2 \cdot 0$ to 14.3 and in asthmatic patients from 1.9 to 13.7 at peak exercise. The increases in adrenaline and noradrenaline in the asthmatic patients did not differ significantly from the increases in normal subjects. Thus a reduced sympathoadrenal response to exercise seems unlikely to be an important mechanism in the pathogenesis of exercise induced asthma.

Circulating catecholamine concentrations increase during exercise in normal subjects. ${ }^{1-3}$ The concentrations of adrenaline found during exercise have been reproduced by low dose infusion and have been shown to cause bronchodilatation in both normal subjects ${ }^{24}$ and asthmatic patients. ${ }^{5}$ Catecholamines may also have indirect effects on airway calibre; studies have shown that stimulation of $\beta$ receptors on pulmonary mast cells inhibits their degranulation ${ }^{6}$ and noradrenaline may have an inhibitory effect on vagal transmission, as has been shown in animals. ${ }^{78}$ Thus a failure of the usual increase in catecholamine concentrations during exercise could contribute to the exercise induced airway narrowing seen in some asthmatic patients. Recent studies, using a modern catecholamine assay, have found impaired catecholamine responses to exercise in asthmatic patients ${ }^{19}$ and have suggested that sympathoadrenal failure may be one mechanism contributing to exercise induced asthma. Larsson, ${ }^{10}$ however, was able to show an adrenaline response to submaximal exercise in asthmatic patients,

Address for reprint requests: Dr K E Berkin, Department of Respiratory Medicine, General Infirmary, Leeds LS1 3EX.

Accepted 15 December 1987 although the increase in both asthmatic and normal subjects was modest. The increase in catecholamines during exercise is dependent on the work load achieved, ${ }^{3}$ and is modest at submaximal work loads. Previous studies in asthmatic patients have used submaximal work loads, and have not shown, with measurements of oxygen consumption, that the work loads achieved were equivalent in the two groups.

In view of these conflicting results and of the important implications of sympathoadrenal failure in asthmatic patients we assessed the catecholamine response to exercise in normal subjects and asthmatic patients, using a modern radioenzymatic assay. "So that they would achieve similar work loads during a maximal exercise test, the two groups were matched for age, weight, and general physical activity. All subjects were familiar with treadmill exercise, during which we recorded oxygen consumption and minute ventilation.

\section{Methods}

Six asthmatic and six normal men with no history of respiratory disease gave informed consent to the study, which had been approved by the hospital ethical committee. The asthmatic patients had a previously 
Table 1 Details of patients and subjects, and peak exercise data

\begin{tabular}{|c|c|c|}
\hline Variable & Asthmatic & Normal \\
\hline $\begin{array}{l}\text { Age (years, range) } \\
\text { Weight (kg, range) } \\
\text { Height (cm, range) }\end{array}$ & $\begin{array}{c}34(17-24) \\
64(50-74) \\
173(165-180)\end{array}$ & $\begin{array}{c}23(21-25) \\
63(46-70) \\
176(178-181)\end{array}$ \\
\hline \multirow{3}{*}{$\begin{array}{l}\text { Peak exercise values } \\
\text { (mean }(\mathrm{SEM})) \\
\mathrm{Vo}_{2}(\mathrm{ml} / \mathrm{kg} / \mathrm{min}) \\
\mathrm{VE}(\mathrm{l} / \mathrm{min}) \\
\text { exercise time (min) } \\
\text { heart rate }(\text { beats } / \mathrm{min}) \\
\text { blood lactate }(\mathrm{mmol} / \mathrm{l}) \\
\text { systolic blood pressure } \\
\text { (mm } / \mathrm{Hg})\end{array}$} & & \\
\hline & $\begin{array}{c}41.4(1.6) \\
62(5) \\
16.7(1.0) \\
190(10 \cdot 7) \\
8.0(1.5)\end{array}$ & $\begin{array}{c}46 \cdot 6(5 \cdot 5) \\
71(5 \cdot 5) \\
17.8(1 \cdot 1) \\
199(2 \cdot 3) \\
8.9(1 \cdot 6)\end{array}$ \\
\hline & $175(17)$ & $187(7)$ \\
\hline
\end{tabular}

documented fall in $\mathrm{FEV}_{1}$ after exercise of at least $15 \%$. At the time of study resting $\mathrm{FEV}_{\text {, values were greater }}$ than $70 \%$ of the predicted values. All patients took inhaled salbutamol when necessary, and one patient was taking an inhaled steroid and one sodium cromoglycate on a regular basis. No drugs were taken for eight hours before the study. Further details of the subjects are given in table 1 .

Subjects attended the laboratory at 9 am after a light breakfast with no drinks containing caffeine. An intravenous cannula was inserted into a forearm vein. The subjects rested supine for 20 minutes, after which blood was taken for measurement of catecholamine and lactate concentrations, and $F E V_{1}$ was then recorded with the subject seated. FEV 1 was measured from a maximum flow-volume curve with a one second marker, obtained with a dry rolling seal spirometer with a flow-volume differentiator (P K Morgan Ltd) and recorded on an $x-y$ ploter (Rikadenki 201T). Three curves were obtained on each occasion and the best FEV , was taken.

After electrocardiographic (ECG) electrodes had been put in position the subjects underwent graded treadmill exercise to exhaustion, according to the Bruce protocol (table 2). Further blood samples for measurement of catecholamines and lactate were taken just before each exercise increment, immediately before completion of exercise, and five minutes after exercise. During each stage of the exercise blood $\stackrel{x}{-}$ pressure was recorded by a mercury sphygmomano- $\overline{\vec{\omega}}$ meter and heart rate was taken from the continuouso ECG recording. Minute ventilation $(\dot{\mathrm{V} E})$ and oxygen 들 consumption $\left(\mathrm{VO}_{2}\right)$ were recorded throughout exer- $\frac{\bar{p}}{\vec{D}}$ cise, a mouthpiece with a low resistance valve being $\mathbb{\Phi}_{\Omega}$ connected to an Oxylog (P K Morgan Ltd), which has 0 been shown to compare well with more complex ${ }^{\mathrm{e}}$ equipment for the measurement of $\dot{\mathrm{Vo}}_{2} \cdot{ }^{12}$ Two and 10. minutes after completion of exercise $\mathrm{FEV}_{1}$ recordings $\vec{\overrightarrow{ }}$ were repeated.

The blood for catecholamine measurements was $\overrightarrow{\vec{x}}$ transferred immediately into cooled lithium heparin tubes, separated at $4^{\circ} \mathrm{C}$, and stored at $-70^{\circ} \mathrm{C}$ until assayed by a radioenzymatic method. ${ }^{11}$ The interassay $\tilde{\tilde{O}}$ coefficient of variation for noradrenaline and adren- $c 0$ aline is less than $12 \%$. Blood for lactate measurements $ᄋ$ was transferred into cooled, prepared tubes and assayed by a method based on the NAD dependent $D$ conversion of lactate into pyruvate with lactate dehydrogenase. ${ }^{13}$

Results are expressed as means with standard errors $\stackrel{\oplus}{\infty}$ in parentheses and statistical comparisons between the normal subjects and the asthmatic patients were made with Student's $t$ test with a modification for multiple comparisons with a control group. ${ }^{14}$ Peak values of adrenaline and noradrenaline concentrations were not $\stackrel{\mathscr{Q}}{\mathscr{Q}}$ normally distributed, so logged values were used for $\unrhd$ statistical analysis.

\section{Results}

The asthmatic patients were similar in age, weight, and height to the normal subjects (table 1). The mean 을 exercise time was slightly less in the asthmatic group $\stackrel{\sim}{\times}$ $(16.7$ (SEM 0.96) $\mathrm{min}$ ) than in the normal subjects $(17.8(1.12) \mathrm{min})$, as were the other indices of peak work load achieved (peak heart rate, systolic blood $\delta$ pressure, oxygen consumption, and minute ventilation) (table 1). These differences were small, however, 의 and not significant. Raised blood lactate concentra- $\rightarrow$ tions confirmed that both groups had achieved anaerobic metabolism during exercise (table 2).

Table 2 Bruce protocol and blood lactate values during exercise

\begin{tabular}{|c|c|c|c|c|c|c|c|}
\hline \multirow[b]{2}{*}{ Stage } & \multirow{2}{*}{$\begin{array}{l}\text { Speed } \\
(\text { mile/h) }\end{array}$} & \multirow{2}{*}{$\begin{array}{l}\text { Incline } \\
(\%)\end{array}$} & \multirow[b]{2}{*}{ Mets* } & \multicolumn{2}{|c|}{ Number reaching stage } & \multicolumn{2}{|c|}{$\begin{array}{l}\text { Blood lactate } \\
(\text { mmolll, mean }(S E M))\end{array}$} \\
\hline & & & & Asthmatic & Normal & Asthmatic & Normal \\
\hline $\begin{array}{l}1 \\
2 \\
3 \\
4 \\
5 \\
6 \\
7\end{array}$ & $\begin{array}{l}1 \cdot 7 \\
2.5 \\
3.4 \\
4.2 \\
5.0 \\
5.5 \\
6.0\end{array}$ & $\begin{array}{l}10 \\
12 \\
14 \\
16 \\
18 \\
20 \\
22\end{array}$ & $\begin{array}{r}4 \\
7 \\
10 \\
13 \\
16 \\
19 \\
21\end{array}$ & $\begin{array}{l}6 \\
6 \\
6 \\
6 \\
6 \\
2 \\
1\end{array}$ & $\begin{array}{l}6 \\
6 \\
6 \\
6 \\
6 \\
4 \\
2\end{array}$ & $\begin{array}{c}1.4(0.1) \\
1.3(0.1) \\
2.0(0.3) \\
3.0(0.5) \\
7.4(1.8) \\
\end{array}$ & $\begin{array}{l}1.2(0.2) \\
1.5(0.4) \\
2.3(0.8) \\
5.8(3.1) \\
7.6(1.9)\end{array}$ \\
\hline
\end{tabular}




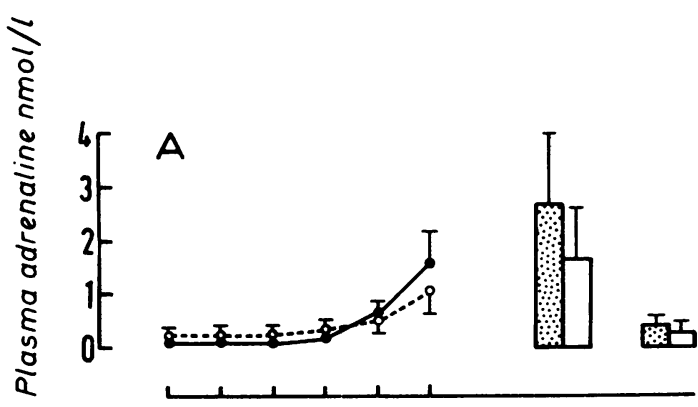

work loads, but they increased more sharply at higher work loads, corresponding to the increase in blood lactate.

The baseline noradrenaline concentration was $2 \cdot 0$ $(0 \cdot 7) \mathrm{nmol} / \mathrm{l}$ in the normal subjects and $1.9(0.8) \mathrm{nmol} / \mathrm{l}$ in asthmatic patients. The peak noradrenaline concentration in normal subjects $(14 \cdot 3(2 \cdot 1) \mathrm{nmol} / \mathrm{l})$ did not differ significantly from that seen in the asthmatic patients $(13 \cdot 7(5.2) \mathrm{nmol} / \mathrm{l})$. Individual adrenaline and noradrenaline concentrations at peak exercise are shown in figure 2 .

\section{Discussion}

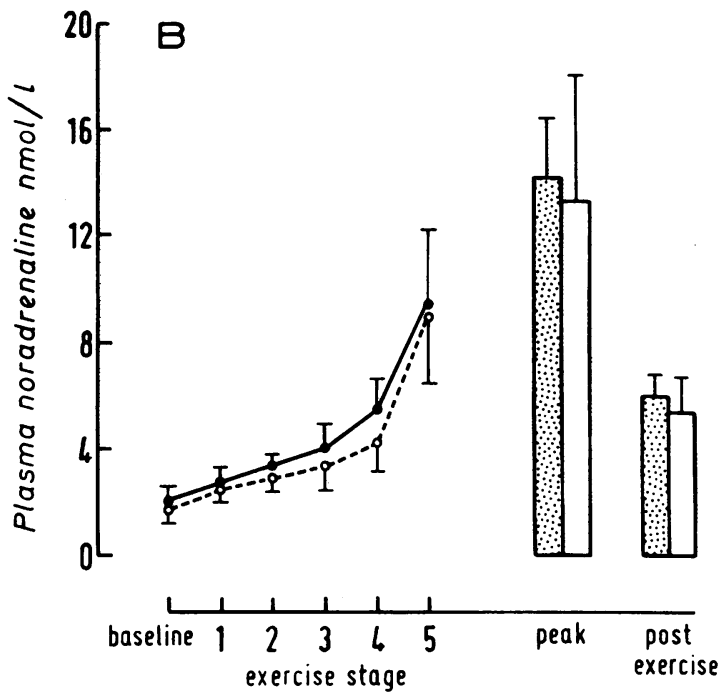

Asthmatic patients achieved work loads similar to those of the normal subjects as measured by oxygen consumption. The other variables recorded (exercise time, heart rate, and minute ventilation) give an approximate indication of work load achieved, but are influenced by other factors such as physical fitness, weight, height, and familiarity with the exercise test in question. ${ }^{15}$ Our patients were judged to be similar in physical fitness and were similar in body weight and height to the control group and all subjects were familiar with treadmill exercise. Hence exercise time, heart rate, and minute ventilation were similar in the two groups.

Both groups showed significant increases in adrenaline concentrations during the exercise test, although

Fig 1 (A) Plasma adrenaline concentrations and (B) plasma noradrenaline concentrations (means and standard errors) before, during, and five minutes after exercise in normal subjects (shaded circles and blocks) and asthmatic patients (clear circles and blocks).

Baseline mean $\mathrm{FEV}_{1}$ was $4 \cdot 1(0 \cdot 2) 1$ in normal subjects and $3.7(0.2) 1$ in asthmatic patients, $91 \%$ $(5 \%)$ of predicted values. After exercise asthmatic patients showed a $20 \%(5 \cdot 3 \%)$ fall in mean $F E V_{1}$, in contrast to the normal subjects, who showed a slight rise in mean $\mathrm{FEV}_{1}$.

Baseline (supine) mean adrenaline concentration in the normal subjects was $0.05(0.03) \mathrm{nmol} / \mathrm{l}$ and in the asthmatic patients $0 \cdot 12(0.04) \mathrm{nmol} / \mathrm{l}$. The peak adrenaline concentration in the normal subjects was $2 \cdot 7(1 \cdot 2)$ $\mathrm{nmol} / \mathrm{l}$ and in the asthmatic subjects $1.6(0.8) \mathrm{nmol} / \mathrm{l}$ (fig 1). These differences were not significant. There was substantial variation in plasma adrenaline between individuals but each individual showed a progressive increase during exercise. The increases in plasma adrenaline concentrations were small at low

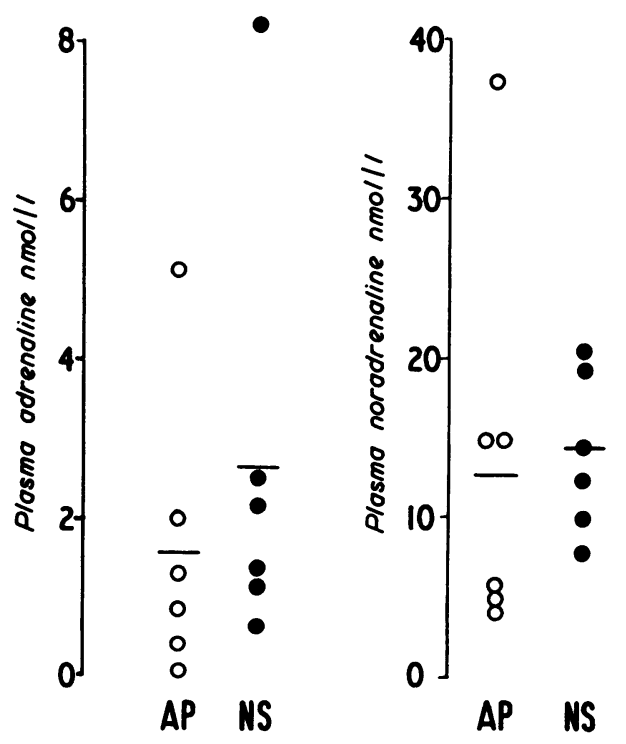

Fig 2 Individual peak plasma adrenaline and noradrenaline concentrations in asthmatic patients ( $A P$, open circles) and normal subjects (NS, closed circles) during exercise (horizontal bar indicates mean concentration). 
the increase was not great until a high work load was achieved and anaerobic metabolism occurred. ${ }^{16}$ Adrenaline concentrations of this magnitude exceed the thresholds at which the metabolic and haemodynamic effects of adrenaline are seen. ${ }^{17}$ The mean peak adrenaline concentration was slightly lower in the asthmatic group, but the difference was not significant. There were individual variations in the peak concentration achieved in both groups and a small difference between normal subjects and asthmatic patients cannot be excluded. A study including large numbers of patients would be required to ensure that a type II statistical error had not occurred. The variability in plasma adrenaline concentrations at high exercise levels has been noted elsewhere. ${ }^{3}$ Clearly, however, both individually and as a group, patients were able to increase adrenaline concentrations during exercise much the same as the normal subjects in this and another study. ${ }^{3}$ Moreover, measurements that reflected sympathetic nerve activity, such as noradrenaline concentration, heart rate, and blood pressure, showed no significant differences between the groups. These observations do not support the suggestion that abnormal adrenaline release or metabolism, or both, or sympathetic nerve failure occur in asthmatic patients.

Several previous studies using the older, less sensitive fluorimetric method for measurement of plasma catecholamines did not detect any difference in catecholamine response to exercise between asthmatic and normal subjects. ${ }^{18} 19$ Two recent studies, however, using a modern and more sensitive radioenzyme assay for catecholamines, have reported a failure of the usual increase in catecholamine concentrations during exercise in asthmatic patients. ${ }^{19}$ In the study by Barnes et al' maximum work load, which appeared to be well matched in the two groups as judged by minute ventilation, heart rate, and body weight, corresponded approximately to stage 4 of exercise in our study. At this point plasma adrenaline concentrations in the asthmatic patients in both studies were similar (about $0.5 \mathrm{nmol} / \mathrm{l})$. The more substantial increase $(1.39(0.18)$ $\mathrm{nmol} / \mathrm{l})$ in the normal schoolchildren studied by these workers may have been due to the children's lack of familiarity with intravenous cannulas and treadmill exercise, in contrast to the asthmatic patients. In the study by Warren et al $^{9}$ the subjects were not familiar with treadmill exercise, which was varied for each subject. Work loads (submaximal) may have been different in the two groups despite similar heart rates during exercise. Moreover, blood was sampled one minute after completion of exercise, at which time plasma catecholamine concentrations are falling rapidly; so the timing of blood sampling would be crucial.

The patients participating in this study had, of necessity, mild asthma as judged by their therapeutic $\vec{F}$ requirements, good exercise tolerance, and near nor- $-\frac{\rho}{-}$ mal resting FEV $_{\text {, values. Would patients with more }}$ severe asthma show a deficient adrenaline response if $\frac{\overline{0}}{\overline{0}}$ able to exercise to an equivalent degree? This seems $\frac{\sigma}{\sigma}$ unlikely, as any important mechanism in the patho- $\stackrel{\square}{2}$ genesis of exercise induced asthma would be expected के to be present in all asthmatic patients. Furthermore, $\overrightarrow{0}$ there seems little doubt that asthmatic patients respond similarly to normal subjects in releasing adren- $\vec{\omega}$ aline in response to insulin induced hypoglycaemia ${ }^{2021} \stackrel{\odot}{P}$ and histamine infusion. ${ }^{20} \mathrm{~A}$ study of patients with $\vec{x}$ acute asthma, however, failed to find any increase $\vec{\omega}$ above normal of plasma adrenaline concentrations. ${ }^{22} \rightarrow$ This was a surprising observation, as a rise in plasma $\tilde{C}_{0}$ adrenaline would be anticipated in such stressful ${ }^{\mathcal{G}}$ circumstances and noradrenaline concentrations were $\stackrel{5}{\supset}$ increased, indicating that the patients were able to $\vec{D}$ mount a normal sympathetic nerve response. Patients with other acute illnesses, such as myocardial infarction, may have increased circulating adrenaline con- $\vec{\oplus}$ centrations, although substantial increases are usually $\oplus^{\circ}$ confined to those with shock. ${ }^{23}$ There has been no identification of a positive feedback system from the lungs to the adrenal medulla whereby bronchoconstriction per se results in adrenaline release, and hypoxia does not appear to stimulate adrenaline $\stackrel{\mathbb{Q}}{\complement}$ output, at least in normal man. ${ }^{24}$ The increases in $\underset{F}{\Rightarrow}$ adrenaline concentrations in stressful conditions such $\frac{\circ}{3}$ as acute asthma may be transient and peak concentrations may occur before admission to hospital, unless the patient is severely compromised haemodynamically. The same authors have subsequently $\overline{0}$ recorded very high adrenaline concentrations (mean $\underset{x}{\stackrel{0}{x}}$ $6.69 \mathrm{nmol} / \mathrm{l}$ ) in two patients who had acute severe asthma resulting in acidosis and carbon dioxide retention. ${ }^{21}$

Asthmatic patients, then, appear unlikely to have deficient sympathoadrenal responses, and this study 은 does not support the suggestion that sympathoadrenal failure occurs during exercise in patients with asthma.

\section{References}

1 Barnes PJ, Brown MJ, Silverman M, Dollery CT. N Circulating catecholamines in exercise and hyperventilation-induced asthma. Thorax 1981;36:435-40.

2 Warren JB, Dalton N. A comparison of the broncho- $\frac{D}{\mathscr{D}}$ dilator and vaspressor effects of exercise levels of adrenaline in man. Clin Sci 1983;64:475-9.

3 Bramnert M, Hōkfelt B. Lack of effect of naloxone in a moderate dosage on the exercise-induced increase in $\vec{D}$ blood pressure, heart rate, plasma catecholamines, $\frac{O}{D}$

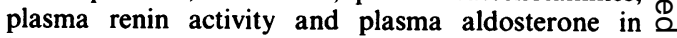
healthy males. Clin Sci 1985;68:185-91.

4 Berkin KE, Inglis GC, Ball SG, Thomson NC. Airway responses to low concentrations of adrenaline and 
noradrenaline in normal subjects. $Q J$ Exp Physiol 1985;70:203-9.

5 Berkin KE, Inglis GC, Ball SG, Thomson NC. Effect of low dose adrenaline and noradrenaline infusions on airway calibre in asthmatic patients. Clin Sci 1986; 70:347-52.

6 Butchers PR, Skidmore IF, Vardey CJ, Wheeldon A. Characterisation of the receptor mediating antianaphylactic effects of beta-adrenoreceptor agonists in human lung tissues in vitro. Br J Pharmacol 1980; 71:663-7.

7 Ito Y, Tajima K. Dual effects of catecholamines on preand post-junctional membranes in the dog trachea. $\mathrm{Br}$ $J$ Pharmacol 1982;75:433-40.

8 Danser AHJ, van den Ende R, Lorenz RR, Flavahan NA, Vanhoutte PM. Prejunctional beta-l-adrenoreceptors inhibit cholinergic transmission in canine bronchi. J Appl Physiol 1987;62:785-90.

9 Warren JB, Keynes RJ, Brown MJ, Jenner DA, McNicol MW. Blunted sympathoadrenal response to exercise in asthmatic subjects. Br J Dis Chest 1982;76:147-50.

10 Larrson K, Hjemdahl P, Martinsson A. Sympathoadrenal reactivity in exercise-induced asthma. Chest 1982;23:297-303.

11 Ball SG, Tree M, Morton JJ, Inglis GC, Fraser R. Circulating dopamine: its effects on the plasma concentrations of catecholamines, renin, angiotensin, aldosterone and vasopressin in the conscious dog. Clin Sci 1981;61:417-22.

12 Jones PW, Wakefield JM, Kontaki E. A simple and portable paced step test for reproducible measurements of ventilation and oxygen consumption during exercise. Thorax 1987;42:136-43.

13 Hadjivassiliou AG, Rieder SV. The enzymatic assay of pyruvic and lactic acids. A definitive procedure. Clin Chim Acta 1968;19:357-61.
14 Dunnet CW. New tables for multiple comparisons with a control. Biometrics 1964;20:482-91.

15 Cotes JE. Lung function: assessment and application in medicine. 4th ed. Oxford: Blackwell Scientific Publications, 1979.

16 Warren JB, Dalton N, Turner C, Clark TJH, Toseland PA. Adrenaline secretion during exercise. Clin Sci 1984;66:87-90.

17 Clutter WE, Bier DM, Shah SD, Cryer PE. Epinephrine plasma metabolic clearance rates and physiologic thresholds for metabolic and haemodynamic actions in man. J Clin Invest 1980;66:94-101.

18 Anderson SD, Pojer R, Smith ID, Temple D. Exercise related changes in plasma levels of 15-keto-13, 14dihydroprostaglandin $\mathrm{F} 2$ and noradrenaline in asthmatic and normal subjects. Scand J Respir Dis 1976; 57:41-8.

19 Chryssanthopoulis C, Barboriak JJ, Fink JN, Stekial WJ, Maksud MG. Adrenergic responses of asthmatic and normal subjects to submaximal and maximal work levels. J Allergy Clin Immunol 1978;61:17-22.

20 Ind PW, Brown MJ, Barnes PJ. Sympathoadrenal response in asthma [abstract]. Thorax 1983;38:702.

21 Clarke B, Ind PW, Mair J, Causon R, Barnes PJ. Bronchodilator and catecholamine responses to induced hypoglycaemia in acute asthma [abstract]. Clin Sci 1985;69:35P.

22 Ind PW, Causon RC, Brown MJ, Barnes PJ. Circulating catecholamines in acute asthma. $\mathrm{Br}$ Med $J 1985$; 290:267-9.

23 Bertel O, Būhler FR, Baitsch G, Ritz R, Bukart F. Plasma adrenaline and noradrenaline in patients with acute myocardial infarction. Chest 1982;82:64-8.

24 Ind PW, Maxwell DL, Causon RC, Brown MJ, Barnes PJ. Hypoxia and catecholamine secretion in normal man [abstract]. Clin Sci 1984;67 (suppl 9):58P. 